Noonan, Caitriona (2014) 'Not a museum piece': Exploring the 'special' occupational culture of religious broadcasting in Britain. International Journal of Media \& Cultural Politics, vol. 10, no. 1, pp: 65-81.

(http://www.intellectbooks.co.uk/journals/view-Article,id=17887/) 
'Not a museum piece': Exploring the 'special' occupational culture of religious broadcasting in Britain

Religion is often regarded as posing a distinct challenge to the occupational norms of cultural production and journalism due to its subjectivities and complexities. Based on research with staff involved in the production of content for BBC television and radio, this article explores the occupational context in which they work. In particular it focuses on the experiences and strategies of the BBC's Department of Religion and Ethics as it attempts to secure its survival as an autonomous production unit. This group of executives, producers, presenters and production staff are in many ways unique because of the professional and social role that they fulfil, most notably through the close historical and ideological ties between religion and the principles of public service.

This research finds a distinct professional identity built around a fusion of public service logic and commercialism, along with the mobilisation of specialist knowledge. This also allows the department to symbolically and discursively separate themselves from other actors in this field as they attempt to reinforce religious broadcasting's professional distinctiveness at a crucial time in the survival of the unit and to highlight the uniqueness of religion as a topic within cultural production.

Keywords: religion, broadcasting, production culture, professionalism, television, radio. 
'Not a museum piece': Exploring the 'special' occupational culture of religious broadcasting in Britain

[T]he idea that you took it and make religion and morality almost like a museum piece and you looked around it was always the wrong approach to religion. It was actually at the centre. (Independent Television Producer)

Many people worry about the marginalisation of religion in modern life. Let me tell you, from where I'm sitting it's front and centre stage: dynamic, complex, potentially explosive. (Mark Thompson, former BBC Director General)

In 2006 New Statesman, an influential British political and cultural magazine, declared on its cover that religion was 'the great issue of our time' claiming it underpinned many of the social, cultural and political debates taking place. Both of the opening quotes from professionals working in the media further substantiate this view of religion as a persistent issue which remains central to a range of everyday experiences, but they also highlight its role in many socio-political concerns. These observations contribute to an on-going debate on the role of religion in the public sphere and the recurrent framing of religion as a contentious social force. Such debate is likely to continue for the foreseeable future as the lived reality of a multicultural society becomes apparent in countries across the globe.

Yet, despite its centrality, the relationship between the media and religion has been difficult. Religion is often regarded as posing a distinct challenge to the professional norms of cultural producers with religion often seen as a "complex and nuanced" (Hoover 1998: 27) phenomenon, and due to a variety of cultural, institutional and economic reasons its treatment in the media has been "troublesome" (ibid: 18). Deuze (2005: 452) argues that the emergence of a multicultural society impacts 
significantly on the workings of media practitioners, for instance challenging established news values and routines. For some critics the response of media professionals to this multicultural shift has been less than accommodating. They argue that in relation to religious coverage overt religious reporting has been marginalized in certain areas (Hoover 1998), with other scholars asserting that such marginalisation further compounds the "misunderstandings and downright bad will in the relationship between religion and the mass media" (Biernatzki 2000: 89). Such social and occupational changes, and the tensions which emerge from within these, are at the heart of this study.

This research examines the interaction of various professional, social and commercial processes and how these impact upon religious output on the main British public service broadcaster, the BBC. In Britain religious content on television (which includes documentaries, dramas, lifestyle formats, discussion programmes, etc.) is being increasingly consolidated to two of the main five terrestrial television broadcasters - the $\mathrm{BBC}$ and Channel 4. On radio it is again the $\mathrm{BBC}$, in particular BBC Radio Four and local radio services, which provide the most faith-based content. ${ }^{\mathrm{i}}$ The $\mathrm{BBC}$ continues to operate quotas for religious output with the BBC Trust stating that the main television channels (BBC One and BBC Two) should broadcast at least 110 hours of religious programming each year with 'some high impact religious programming in peaktime' (BBC Trust 2013a), while Radio Four should broadcast at least 200 hours of original religious programming each year (BBC Trust 2013b). ${ }^{\text {ii }}$ However, despite these commitments the resources dedicated to religious broadcasting continue to fall (Ofcom 2013). ${ }^{\text {iii }}$ 
The majority of religious content for these television and radio platforms is produced by either the independent production sector or BBC in-house production. The BBC's own Department of Religion and Ethics (DRE) continues to be the main source of specialist religious production (Ofcom 2013) producing content for all BBC platforms. This research examines the narratives of staff in this production unit as they pursue particular agendas, promote certain values and position themselves in the market. This becomes particularly important as they formulate strategies for survival in a more internally and externally competitive broadcasting landscape. There is greater pressure for areas of programming traditionally seen as part of a social responsibility (such as religion, arts, natural history) and which were previously sheltered under the umbrella of PSB, to now position themselves as strategically important. The research highlights some of the strategies for survival and the ways in which professionals give meaning and respond to institutional politics.

The research finds that there is a drive among producers to preserve religion's place as a public sphere concern, particularly through the inclusion in the schedules of sustained critical commentary, in-depth interviews, expert discussion and serious factual programmes which deal with the more controversial socio-political dimension of religion. Furthermore, in this study the Department of Religion and Ethics mobilise their expert knowledge, the execution of professional standards and their civic role to symbolically and discursively separate themselves from other producers in an attempt to reinforce religious broadcasting's professional distinctiveness and the uniqueness of religion as a topic within cultural production. 


\section{Cultures of production}

This research contributes to the long-established tradition of research into the production of texts and cultural material, however it provides insight into an area of programming which has been largely overlooked in academic inquiry and brings fresh perspectives to lived experience of cultural production.

Cultural production 'unfolds as a collective, daily cultural performance involving symbolic codes, [and] conventionalized power hierarchies' (Caldwell 2008: 342), shaped by institutional cultures and social, commercial and technological change. It is shaped by complex social and political arrangements between groups underscored by rules (conscious and unconscious) as each group seeks to exercise control and negotiate power (Bourdieu 1993). Researchers in this field have tried to expose the taken for granted rules, discourses and norms which condition cultural production in a number of contexts (Caldwell 2008; Cottle 1997, 2004; Steemers 2010; Tunstall 1993) and have sought to understand how professional identity is understood, managed and maintained while attempting to link 'corporate macrostrategies and human microstrategies' (Caldwell 2008: 34).

However, such a potentially homogenous view of cultural production should be framed against the subject-specific hierarchies which often exist within broadcasting. Tunstall's (1993) work uncovers various 'private worlds' within genres where each has its own distinct norms and where specific values circulate. Deuze (2005: 445) also argues that how professional ideology is 'interpreted, used and applied' differs by

group. For example, Schlesinger states that although Public Service Broadcasting (PSB) values are still present in the broadcasting industry, "the extent to which PSB 
purposes can be and are mediated to employees through their production contexts and work practices will vary considerably, depending on the organisation for which they work and the markets to which the company's output is orientated" (2004: 11). Indeed the concept of a discrete subject-specific production culture is often mobilised by occupants in both symbolic and practical ways: 'to gain and reinforce identity, to forge consensus and order, to perpetuate themselves and their interests, and to interpret the media as audience members' (Caldwell 2008: 2). In this way each group vies for resources and power in a competitive broadcast market where an increasingly critical and unpredictable audience, along with heightened commercial pressures, have led to ever more precarious labour conditions.

In this competitive and changing broadcasting environment there has been a drive to underscore the professionalism of broadcasting and this has had an effect on the commissioning and production process within the $\mathrm{BBC}$ and indeed in the wider production milieu (Born, 2004; Cottle, 1997). Professionalisation involves the application of specialized knowledge or skills, and grants privileged status to an occupational role. Boundaries are demarcated to exercise jurisdictional control and to avoid intrusion from external actors (Paquette 2012; Waisbord 2012). This status is characterised by greater autonomy, the setting of norms and acceptable standards, and the mobilizing of a certain unique 'symbolic capital' (Waisbord 2012: 12). For the researcher the concept of professionalism is helpful to understanding how one area of production exercises control while simultaneously demarcating boundaries with other fields to produce a distinctive identity. It is also a useful path to explore similarities and differences between professional groups (ibid.). While changes in technology and audience activities have certainly called into question some forms of professional 
creative identity (e.g. the professional journalist), professional identity remains salient in the realm of religious broadcasting, as discussed later. Further, as public service broadcasting is in flux, such uncertainty can often trigger professional pressures to symbolically highlight distinction and innovation in often public ways (Caldwell 2008). Appreciating such a struggle and how it contributes to a more conceptually sophisticated understanding of 'professional pragmatics' (Cottle 1997) in an evolving media and cultural landscape warrants further academic attention.

The research documented here draws mainly on the narrative accounts of producers and executives (i.e. heads of department, commissioning editors and channel controllers) engaged with the BBC's Department of Religion and Ethics. The department crosses both radio and television though staff tend to specialise in one medium. Religious production, in comparison to other 'private worlds' (Tunstall 1993), is fairly stable in terms of personnel as many of the producers in this unit have worked for much of their professional careers in this area. Further, it comprises a relatively small production community and so interviews were also conducted with the independent production sector (who also supply content to BBC television and radio) and those more widely involved in the politics of religious broadcasting in the United Kingdom (e.g. former staff who still contribute to, and advise on programmemaking but on a more ad-hoc basis). A total of twenty-three semi-structured interviews were conducted during 2007-09 with producers forming the bulk of the sample (14 in total). "Television is a producer's medium" (Newcomb and Alley 1982: 69) where, despite television production being a highly collaborative activity, in broadcasting the producer remains a defining site of 'artistic authority in current industrial practice' (Caldwell 2008: 17). However, Caldwell (2008) warns that the 
researcher must be alert to the motives of self-interest which may condition production narratives. This is reiterated by Paquette (2012) who also asserts that narratives of professional identity are 'the result of the individual's negotiation with organizational contingencies' (2012: 15). The result is a framework of rituals, symbols and worldviews which are constantly constructed and reconstructed often to further a personal or professional stance.

\section{Religious broadcasting in a shifting landscape}

The global religious landscape has been radically transformed in the past few decades. According to Davie et al:

The $20^{\text {th }}$ and $21^{\text {st }}$ centuries have witnessed not only the decline but also the reinvention and resurgence of traditional religions alongside the rise of new forms of religion and spirituality. Some of the resurgence has been dramatic both in its nature and its political consequences. (Davie et al 2003: 2)

In this complex milieu elements of secularisation and sacralisation co-exist. On the one hand traditional religious institutions have faced a sustained cultural challenge to their authority. In Britain 'the Christian churches have lost their ability to shape popular thinking' (Bruce 1995: 71), this in turn has had a knock-on effect to their visibility and representation in the media. On the other hand, there has been an increased interest in eastern faiths, along with eclectic New Age spiritualities encouraging personal sacralisation. Commentators also pronounce the United Kingdom a post-Christian multi-faith society; currently the second largest institutional religion in the UK is Islam - comprising $4.8 \%$ of the total population (UK Census 2011) - followed by Hinduism, Sikhism and Judaism in terms of number of adherents, while there are also a growing number of individuals who profess no religious 
affiliation. All of these shifts in the religious landscape point to a complex clash between religion and secularity, tradition and modernity, personal and collective. The result is that the character and nature of religion itself is changing (Hoover, 1998; Davie et al, 2003) and it is within this shifting social and cultural context that religious broadcasting operates.

In the realms of both television and radio broadcasting such a shift is discernable in much of the programming. As religious institutions decline in legitimacy so does the tendency to treat them with deference (Hoover, 1998). This is especially pertinent in relation to the $\mathrm{BBC}$ who initially fulfilled a proselytising mission and who were historically positioned as 'defender' of the Christian faith in Britain (Wolfe 1984; Noonan 2013). The remnants of these past agendas can be seen in the continued transmission of programmes such as Songs of Praise (BBC 1, 1961 - ) and Thought for the Day (Radio 4, 1957 - ). ${ }^{\text {iv }}$ Furthermore, through genres like lifestyle and reality television programme-makers have attempted to bring the private language and experience of religion into the public sphere (Hoover 1998; Noonan 2011), most notably with programmes like Extreme Pilgrim (BBC 2, 2008) and The Monastery (BBC 2, 2005). A number of other religious programmes (including An Island Parish (BBC 2, 2007 - ), The Life of Muhammad (BBC 2, 2011), In the Footsteps of St Paul (BBC 1, 2012), The Preston Passion (BBC 1, 2012)) have enjoyed ratings or critical success, helping to draw renewed attention to the creative potential of the genre and, perhaps most significantly in today's broadcasting landscape, securing financial returns through overseas sales. 
However, such successes should be viewed cautiously. The concept of the public interest has been central to the inclusion of religion since radio was established in the UK (Wolfe 1984) and religion continues to be part of the BBC's commitment to the public interest (BBC Trust 2013a, 2013b). However, this bond between PSB and religious broadcasting has changed considerably as the definitions and expectations of both have evolved. In addressing its public service commitment the BBC's broad mission is no longer solely about addressing a social need, but also about competing in the marketplace and delivering value in relation to public funding (Born 2004; Padovani and Tracey, 2003). This means there is greater pressure for all areas of programming to deliver on this strategy for the Corporation. Even programming traditionally seen as part of a social responsibility, and thus traditionally offered 'protection' through policies like dedicated scheduling and programme quotas, are not immune to this change and they too must now compete for resources, programme slots and commissions. Change has been felt acutely by the Department of Religion and Ethics which has also had to negotiate wider policy decisions, such as moving the unit out of London to Manchester in the mid-1990s and the loss of key formats like the religious current affairs strand Everyman (1977-2005). As the independent sector continues to grow in size and confidence debates also continue about the future of inhouse production more widely at the BBC (Broadcast 2014, The Work Foundation 2005), and at various times in its past critics have argued for DRE to be disbanded and subsumed under factual programming for both financial and editorial reasons. Therefore, a battle for DRE's autonomy continues to be fought. 


\section{Reconciling market logic and public interest}

The evolution of PSB has seen a clear shift away from judging public service broadcasters on the intangible soft criteria which were concerned with content towards a plethora of economic and financial norms. A tension develops between the view of broadcasting as an expression of cultural values and the view that it is predominantly a commercial activity; a tension which is actively negotiated by many genres today.

The 'ecology' of religious broadcasting offers a valuable example of some of the tensions within PSB and an insight into the strategies adopted by staff working within this context. Due to religion's importance on so many levels, what the former Commissioning Editor for Religion termed 'big stuff', there was a clear attempt amongst interviewees to reconcile the traditional vision of PSB, in terms of giving voice to diverse minority interests and the treatment of complex ideas, with the current focus on professionalism and value for money:

The religious appetite is perfectly strong and out there, what we got to do is come up with the types of programmes that will really grab audience so that it's not a public service box ticking exercise but audience grabbing propositions. And I think we can do that. (Head of DRE)

Securing ratings success was necessary in order to deliver value to the Corporation, to demonstrate the ways in which religion could appeal to the mainstream, and to compete for much needed resources internally. Without these programmes their legitimacy and weight as a distinct production unit would be under further threat. Like this interviewee recounts here, the line between cost and public interest was one they often walked:

The BBC should have had more freedom than anyone else because we weren't tied to getting specifically big audiences, we had the public service remit. But all the television controllers that I worked with were 
constantly anxious to know what size of audience we were going to get. How much money it was going to cost? [...] The controller would actually be anxious "why are you spending all that money on this one if it's not going to get a big audience". (Former Head of DRE)

Along with an attempt to control budgets another reason posited for the tension between producers and higher levels executives related to differing backgrounds and identities. That controllers, commissioners, managers and trustees came from a narrow social grouping, what one respondent lamented as "liberal left of centre, Guardian readers, not religious who are quite young relative to the rest of the population" (Producer/Presenter), became problematic in terms of the value this group placed in religious broadcasting. The effect of this exclusivity was that religion as an important theme was felt to be largely dismissed in the upper levels of the BBC hierarchy leading to what on one occasion was emotively termed a "failure of imagination" (Producer/Presenter) amongst management. The interviewees claimed that this indifference from management towards religion was acutely evident in the lack of formal strategy for religion at that time:

[I]f you were to ask for example what is the role of religion on BBC 1, ask the controller, he would tell you Songs of Praise, he wouldn't tell you anything else ... What's the role of religion on BBC 2 , I don't know, and no one else does. What's the role on BBC 3? What's the role on BBC 4? To take the odd documentary particularly if they have an extreme title but there is no strategy. If you ask what is the editorial strategy for religion and ethics on 1,2,3, and 4 ? There is none, there is none that is published. (Producer)

This respondent felt this lack of strategy limited the genre's long-term strategic development at a crucial time for both the unit and the wider BBC. However, the commissioning editor for television refuted claims that there was no cohesive strategy and listed a number of areas where he was keen to commission content. Therefore, it seems that there is more a failure to communicate a clear, consistent or accepted plan rather than a lack of a strategic direction altogether. 
A further concern related to the nature and style of programmes being broadcast. For some commissioning attention was overly concentrated on an increasingly narrow range of entertainment-based formats which focused on novel engagement with traditional faith (such as The Monastery). This meant that their limited resources were being diverted away from more serious journalistic approaches to the topic of religion:

What the BBC doesn't do very much of [and] we should be doing more about, is when those belief systems come into contact with how people live their lives, which is the whole area of ethics and current affairs. (Series Producer/Editor, Songs of Praise)

The pushing of formats about faith as it is lived by the individual, while lucrative and part of a wider aesthetic drive in broadcasting, meant that certain topics were being neglected or overlooked according to this interviewee, particularly in relation to the role of faith in socio-political debates:

[W]e need people who understand religion and where you need a forum for people of different religious faiths to come together and where you need to educate all of us about the other [...] it is a central purpose for what the $\mathrm{BBC}$ would now define as one of its purposes, citizenship and community. (Producer/Presenter)

However, this interviewee goes on to argue that this purpose is not being fulfilled as a result of institutional pressures and budget cuts:

$[\mathrm{P}]$ recisely at this moment, What's it doing? Slashing jobs in the religious department ... no core output ... it's a scandal and a failure. (Producer/Presenter)

Despite an expanding sphere for news and information, the argument was repeatedly made that there were few spaces, particularly on television, for meaningful and regular discussion of religious issues. 
Here, in particular, a distinction was evident between television and radio. In recent years, radio has been a key platform for religious output due to the cost efficiency of the medium and the "special nature of the radio audience" (Contributor to Thought for the Day):

I think it has something to do with the medium. Religion has adapted much better to radio than it has to television. Part of that has to do with costs. [...] I think radio is also a medium to discuss ideas, radio is so much better than television. (Former Head of DRE)

[Television] can't sit still, it's a kind of attention deficit disorder really and I don't think that religion is very well suited to that kind of manic pace and flitting around and grasshopper mentality. Religion requires deeper thought and greater patience and it requires some kind of personal connection and I think radio is fantastically good at that. Speech radio is fantastically good at somebody connecting through the airwaves with a person. (Former Head of DRE)

For radio there hasn't been the same desperate search for popular programming. (Former Head of Religious Programmes TV)

Compared to television, radio has not received the same 'critical and public attention' (Hendy 2007: 395) from both audiences and media professionals. It is often conceptualised as a 'secondary medium' despite its characteristics: the distinctive way it invokes the audience's imagination and its ability to create an inward and intimate medium (Crisell 1994). These characteristics mean that programming at the level of personal experience work well on the medium allowing the intimacy of personal faith to be conveyed in various textures, tones and styles, achieving what one interviewee regarded as 'more authentic programmes' (Radio Producer). However, while this appeal to the subjective has been a feature, rational and informed debate has also been part of the mix of religious programming on radio (partly due to the cost effectiveness of these formats compared to television). This is particularly evident in the schedules of Radio 4 where demanding programmes dealing with the critical exchange of ideas 
(e.g. Moral Maze 1990 - ) along with sustained reporting of religious current affairs (e.g. Sunday 1970 - ) are part of the regular schedule, often at peak-time listening.

Overall, these professionals saw it as their duty to offer the topic in a way that transcends the sole aim of entertaining the public, an aim which they often felt compelled to prioritise because of its ability to engage mainstream audiences (Cottle 1997) and its use of the potentially less controversial subject of personal faith. Nevertheless, these producers were keen to engage with more contentious areas of debate and ensure these approaches remained part of the public agenda; although realising this ambition, particularly on television, has been difficult. This is largely due to the commercial and institutional factors which impede it, such as decreasing budgets, staff cuts and tentative support from senior executives.

\section{Boundaries drawn and dismantled}

While keen to do more, the interviewees also recognised that religion is not the sole preserve of religious producers, and the contribution of the news department and current affairs producers impacts very much on their aims for religious content. Following events like the London bombings in 2005, religion was back on the agenda for many of those outside the specialism of religion. According to the interviewees this had a direct affect on their work; now news and current affairs were treading on what should have been their patch:

[I]t was a bit of a paradox because suddenly everyone was interested in religion and in a kind of ironic way it made the job much harder because suddenly current affairs producers, documentary producers, art producers, everyone was suddenly very interested in religion. (Former Head of DRE) 
It's getting harder because everyone is getting interested in religion; it's the global agenda. The Today programmes are chasing stories that we traditionally were the only ones particularly interested in. (Radio Producer, DRE)

Interestingly, although the department wanted to do more in the area of current affairs, religious producers were keen to distance themselves from the traditional news approach to stories relating to religion. They drew sharp distinctions between their culture and the culture driving other departments distinguishing their professional judgments from the narrow focus they felt that news journalists often employ. For instance news reports, in particular, did not adequately contextualise the religious element within the story focusing only on a specific type of coverage:

I mean current affairs do religion brilliantly well at the sharp end but there is no back-story, there is no deep analysis and ... religious current affairs has become the preserve of the extremists. (Head of DRE)

They suggested that these outlets provided a certain kind of coverage which foregrounded the extreme aspects of religion and many of these issues needed to be communicated in a more nuanced and informed way. In 2006 the BBC's Charter Review Committee echoed this argument. Within the genre of news, their report reminded the $\mathrm{BBC}$ that objectivity and contextualisation were central to effective news reporting. Specifically it criticised the $\mathrm{BBC}$ for failing to provide sufficient background to religious stories, particularly those stories involving conflict between religious groups. Resolving this failure and improving the competencies of reporters were its main recommendations in this area, though the report retreated from making any practical suggestions or interventions.

The interviewees were also keen to reiterate the autonomy within their professional approach to programmes, even if it was not a norm usually associated with the genre: 
It shocked, I think, some Christian people that we could treat the church rather roughly at times. On the other hand, a lot of people appreciated that it was doing a truthful and professional job, it didn't particularly mean we were anti; we were just detached. (Former Head of DRE)

So we could be critical of the churches. We could subject the church and other religious leaders to rigorous interviewing and investigation or as you might say investigative reporting. (Former Head of DRE)

Of course it's a generalistic programme for the BBC so it has to retain an impartiality, but in my time I always felt that Sunday didn't duck, you know the whole debate about gays in the Church of England, I think we took it pretty much head on. (Former Head of DRE)

They attributed the success of Sunday, the only religious news and current affairs programme on network radio and their main outlet for religious journalism, to the careful execution of accepted journalistic principles like objectivity and impartiality. Again, here the symbolic and tangible importance of radio output to religious broadcasting and the department's ambitions is visible. The programme includes interviews with senior religious officials, coverage of the major faith conferences, and debates on topical religious stories. As a result of its journalistic principles Sunday, they argued, has been able to:

I would say, and I said it before, to get under the skin a bit of stories maybe more than other news programmes have, particularly when it comes to religious stories. (Radio Producer, DRE)

They drew curious parallels between Sunday and the BBC's flagship radio news programme, Today (BBC Radio 4, 1957 - ) recognising that the well-established tenets of the BBC's approach to news play a distinct role in the success and legacy of both programmes.

In order to fulfil the brief associated with a programme like Sunday, maintaining congenial relationships with faith groups and other stakeholders was essential. However, while interviewees defended religion they were careful to not express their support for any one faith group: 
It [Sunday] allowed all sorts of voices to be heard many of which were very hostile. (Former Head of DRE)

Principally the interviewees felt they had a part to play by educating society on the intricacies of various religious traditions and histories while also providing a forum for debate where all voices could be heard. The free competition of ideas and opinions between diverse viewpoints continues to be regarded as essential for delivering on the values of public service. This focus on inclusion, a goal contested throughout religious broadcasting's history (see Noonan 2013; Wolfe, 1984), was important and the producers attributed any failures in this area to external forces outside their control, such as the failure of certain groups to engage with the media or provide suitable material.

Another distinct feature of their professional identity was the crucial role played by passion for the topic of religion. This passion was deemed particularly important for key strategic positions within broadcasting (such as heads of departments and commissioners) who have the power to decide the content and its approach:

You expect people running their department (it's true in science), is a passion for the subject. [...] You want them to have a passion for the subject matter as well as be a realist (Presenter/Producer)

[I]t is a problem because you wouldn't have someone fighting for Natural History who didn't have watery eyes at a sunset over the Serengeti. You got to be excited about the subject. (Former Head of DRE)

The appointment of Alan Bookbinder as head of department in 2001 was a key element in this argument. Bookbinder was widely seen as a very good programme maker but had little direct involvement with the department prior to his promotion. More importantly, he was the first ever agnostic Head of Religious Broadcasting at the $\mathrm{BBC}$. His appointment came as a surprise to many in the $\mathrm{BBC}$ and caused a ripple of discontent amongst religious observers outside the Corporation (Lister, 2001). 
Like the question of cost discussed earlier, Bookbinder's appointment reveals another site of tension between the BBC's executives who favoured a more managerial approach, and the department who wanted a more fervent leader with the will-power and commitment to fight for commissions and resources. This signals the battle for control of the religious agenda articulated through a discourse of authority, appropriate representation and critical questions of leadership.

Creating professional boundaries has a valuable function as it allows these producers to define and control the 'rules' of religious broadcasting as they try to encourage and facilitate public religious debate. For these producers they reject some of the ways religion is handled within the traditional news agenda (which they associated with immediacy and extremism) in favour of a more complex and inclusive presentation of events. However, at other times they draw on the ideologies of journalism such as objectivity and impartiality to explain the importance of formats like Sunday demonstrating the ways in which boundaries become malleable and flexible (Waisbord 2012: 64) at various times in responses to institutional and bureaucratic forces.

\section{'Trample on the stuff of people's souls': self-image and authority}

In the past certain in-house production units have been denounced as uninventive (Steemers 2010). Religious broadcasting has also been stigmatised as 'insular and uninformative' and some of its output regarded as falling below accepted standards of quality (Ofcom 2005). For this reason, ensuring that the unit demonstrates its professionalism in the present and offers clear value for money take on greater 
institutional significance if it is to avoid being 'ghettoised' in the professional hierarchies of broadcasting - a fate befallen other niche areas of programming (Cottle 1997).

One of the main arguments which emerged from the interviews was that these professionals wanted to stake their authority within the realm of broadcasting and they were clear that they offered their own distinct perspective to the coverage of religion. They mobilised their knowledge of the field as a further part of their own self-identity and as part of their rationale for having a dedicated unit covering religious and ethical content. Having a specialist unit interested in pursuing those stories deemed not 'news worthy' became essential to their public interest arguments and they argued that there were 'other aspects of religion which occupy an awful lot of the time of a religious department' (Former Head of DRE) such as reporting on developments in doctrine, institutional politics within faiths and covering major religious festivals and events.

Specialist knowledge of religion and its associated institutions, traditions and history was a key part of the self-image which many of these professionals mobilised and projected as part of their unique 'symbolic capital' (Waisbord 2012):

I do think that religion and its observance, and its history, and its complications and confusions and its own internal problems are sufficient of a specialism to merit trying to employ people specifically to cover that specialism. (Commissioning Editor Specialist Factual, Radio 4)

[I]t seemed to me that religion is a specialist subject. It's as much a specialist subject as sport, or art, or science or anything else and you have to have people who know something about it ... it has a whole theology, it has history, it has a whole kind of knowledge about the way churches work. A lot of the department's broadcasting was from churches and you had to know the difference between this church and that church; how to 
keep an ecumenical balance. A whole series of semi-political issues as well as technical issues that made it important that you had someone who was a specialist in religion. (Former Head of DRE)

The benefit of this knowledge is important externally if these producers are going to maintain their legitimacy, authority and credibility with audiences and stakeholders.

The 'special' nature of religious broadcasting comes to the fore:

This area, perhaps more than any other, where you do need to know what on earth is going on and terminologies because you can make mistakes which trample on the stuff of people's souls. (Independent Producer)

[I]t's like any specialist area, you got to appeal to the wider audience but you got to maintain the trust and confidence of the specialist audience. I think that's absolutely vital and I think in a specialist area like religion there is the scope for a real howler. (Radio Producer)

I have heard programmes on religious topics where people have made fundamental errors. They just don't know the subject enough. It's important that the producer does otherwise they'd be seduced by contributors who come along with some sort of spurious claim and they can't see through them. (Former Head of DRE)

Respondents were clear that this knowledge was important if broadcasters were to avoid making mistakes and causing unnecessary offence to viewers and listeners. It also highlights the range of possible audiences which they attempt to address - one which is informed and erudite on religious matters, and another perhaps more mainstream and less religiously inclined.

The interviewees' advocacy of specialist knowledge ties their collective professional identity to their ability to pass editorial judgement on the worthiness and credibility of stories. Further this specialist knowledge allows them to go beyond an entertainment provision solely and to offer an adjunct to standard news reporting. However, although the interviewees work hard to articulate the function of their specialist knowledge, they claim that the value of their 'symbolic capital' is not reciprocated within the wider culture of the $\mathrm{BBC}$, as these experiences suggest: 
This was disputed you see by other departments who said "Everybody knows about religion" and it's a fascinating thing this. In things like the Programme Review Boards where the heads of various departments meet every week to talk about programmes, if you said to them "Well, anybody knows about science, you don't have to have a degree in science", "Everybody knows about politics", there would be outrage. This [religion] is a specialism. (Former Head of DRE)

When I used to go to Radio 3 Talks meetings I would be constantly amazed at how people could be utterly philistine and ignorant about religion, whereas if I exhibited the same ignorance or philistine approach to say Shakespeare, I would be regarded as a heathen stroke peasant. And yet in that world its perfectly acceptable [...] Being ignorant about religion would not count in the same way as being ignorant about the semiotics of Coronation Street or having a vague sense of who is in the government. (Former Head of Religious Television)

Furthermore, those from the independent sector also questioned the need for specialist knowledge:

One of the biggest and most interesting moves that broadcasters have made is to take subjects like religion and throw them to the non-specialists. What does an entertainment factual indie make of the Passion? They won't be burdened down in one way by the intricacies and insight of a theology background. (Independent Producer)

The independents continually highlighted the importance of bringing other expertise into the production mix for projects and felt this was key to maintaining any "renaissance" the output was to enjoy. Therefore, if religion is not seen as significant (either institutionally or culturally) or if religious broadcasting is seen as not needing specialist knowledge then it affects whether the subject and the department have a future.

\section{Conclusion: a 'special' status for religious production?}

In the face of social, market and institutional change a shared professional ideology is discernable from the accounts given by those working in and around the Department of Religions and Ethics. Firstly, there remains a distinctive logic orientated to the 
public interest but at the same time acutely aware of the need to operate commercially through more mainstream content. Negotiating these various aims is a constant part of their occupational culture. These cultural producers articulate their commitment to the delivery of content which allows a variety of viewpoints and ideas to be heard and which provides space for the informed debate about the socio-political impact of religion in our society today. While to some extend this is being achieved through their radio provision, television is proving more troublesome due to the costs, expectations and the styles of presentation associated with the medium. Secondly, due to what they regard as the special nature of religion as a topic, the mobilisation of specialist knowledge became an embedded part of their professional identity and a key site in the struggle for sovereignty. For the interviewees this resource allowed them to make important editorial judgements, underscoring their value both institutionally but also as part of their working in the public interest. Finally, their professional culture can also be seen in the ways in which they operate in relation to, but distinct from, other fields; in this study these fields include the news and current affairs department, BBC management and religious groups. The interviewees often engaged in 'boundary work' (Waisbord 2012) either linking or setting themselves apart from these fields demonstrating the ways in which these groups exist in a permanent and evolving tension.

At times when interviewing long-serving members of the Department of Religion and Ethics it seemed like they were 'cast adrift' in their institution. At the forefront of their resistance and response to the changes happening within the $\mathrm{BBC}$, the broadcasting market and to the ideals of public service, was their claim for autonomy and the retention of their privileged position in the broadcasting framework. In some 
ways this strategy can be seen to be working (Ofcom 2013), however, market forces and the contested value of their specialist input remain significant threats to the department's future as a distinct production unit. ${ }^{\mathrm{v}}$

While the United Kingdom has been the context for this study the pressures on PSB and the occupational culture which supports this are present in other national contexts. European models of PSB are under threat as a result of growing competition in the broadcast markets, digital provision which makes the distribution of content more cost effective and a neo-liberal approach to television governance and trade. Equally debates about the place of religious debate in the public sphere and the role of broadcasters in delivering this are prevalent both in Europe and beyond. Furthermore, religion has served as the microcosm within which to observe some of these issues. Other genres associated with public service ideals face many of the same challenges and cultivate their own responses. For instance the cultivation of specialist knowledge (or 'symbolic capital' (Waisbord 2012) is not unique to the area of religion (operating in arts, music, sport, natural history, etc). It is hoped that this research operates as a fruitful path to explore the similarities and differences in these 'private worlds'. How these worlds survive, thrive or disappear in a changing broadcasting landscape certainly warrants further academic attention.

However, while some of the experiences documented here may resonate transnationally and across genres, this study is a snapshot at a particular historical moment in broadcasting and cultural production; the specific occupation experience which was examined here is disappearing and unlikely to be replicated in the future due to changes in media labour and financial pressures within the system. Niche 
genres struggle to command resources and autonomy within public broadcast systems compelled to compete; internal production becomes increasingly unattractive as the independent sector makes increasing gains in the commissioning systems; subject specialism makes way for flexible working and transferable skills. For many of those interviewed the Department of Religion and Ethics (and its predecessor, the Religious Broadcasting Department) has been their 'home' for much of their career and such stability seems out of step with today's changing production ecology. At the time of the research the BBC's iPlayer was still in its infancy and beyond offering further programme information on their website few of the producers considered multiplatform strategies to be part of their everyday routine. Of course, in the intervening years this has changed radically and today audience interactivity, multi-platform distribution and converged content are the norm for producers, commissioners and audiences in all genres, including religion.

However, while this study may well chart an evolving, or even disappearing occupational culture, it does demonstrate the complexities of production as it is negotiated on a daily basis. In the face of competition, commercialism and managerialism, cultural producers do not easily succumb to outside forces and react in multiple and often intriguing ways.

\section{References}

BBC Trust (2013a) BBC One Service Licence.

http://downloads.bbc.co.uk/bbctrust/assets/files/pdf/regulatory_framework/service_lic ences/tv/2013/bbc_one.pdf Accessed 27 January 2014.

BBC Trust (2013b) Radio 4 Service Licence.

http://www.bbc.co.uk/bbctrust/our_work/services/radio/service_licences/bbc_radio_4. html Accessed 27 January 2014. 
BBC Trust (2006) BBC One Service Licence.

http://www.bbc.co.uk/bbctrust/assets/files/pdf/regulatory_framework/service_licences /tv/tv servicelicences/bbcone servicelicence 18dec2006.pdf Accessed 27 January 2014.

Biernatzki, William E. (2000) Twenty Years of Trends in Communication Research. Communication Research Trends, Vol. 20, No. 1 - 4.

Born, Georgina (2004) Uncertain Vision: Birt, Dyke and the reinvention of the BBC. London: Random House.

Bourdieu, Pierre (1993) The Field of Cultural Production: essays on arts and literature. Cambridge: Polity Press.

Broadcast (2014) Pact: BBC quotas will change. 10 January.

Bruce, Steve (1995) Religion in Modern Britain. Oxford: Oxford University Press. Caldwell, John (2008) Production Culture: Industrial reflexivity and critical practice in film and television. London: Duke University Press.

Cottle, Simon (1997) Television and Ethic Minorities: producer's perspectives. Aldershot: Avebury.

Cottle, Simon (2004) Producing Nature(s): on the changing production ecology of natural history tv. Media, Culture and Society. Vol. 26, No. 1, pp: 81-101. Crisell, Andrew (1994) Understanding Radio. $2^{\text {nd }}$ edition. London: Routledge Davie, Grace; Heelas, Paul \& Woodhead, Linda (eds.) (2003) Predicting Religion: Christian, secular and alternative futures. Hampshire: Ashgate Publishing Ltd. Deuze, Mark (2005) What is Journalism: Professional identity and ideology of journalists reconsidered. Journalism. Vol. 6, No. 4, pp: 442-464. Hendy, David (2007) Life on Air: a history of Radio Four. Oxford: Oxford University Press.

Hoover, Stewart (1998) Religion in the News. Thousand Oaks: Sage Publications. Lister, David (2001) BBC Appoints an Agnostic as Head of Religious Programmes. The Independent. 12 July. http://www.independent.co.uk/news/media/bbc-appointsan-agnostic-as-head-of-religious-programmes-677424.html Accessed 16 March 2008. Newcomb, Horace \& Alley, Robert (1982) The Producer as Artist: commercial television. In: Ettema, James \& Whitney, Charles. Individuals in Mass Media Organizations: creativity and constraint. Beverley Hills, CA: Sage Publications: pp 69-90. 
Noonan, Caitriona (2011) 'Big stuff in a beautiful way with interesting people: the spiritual turn in UK religious broadcasting'. European Journal of Cultural Studies, Special Issue: Religion, Media and Social Change. Vol. 14, Issue 6, pp: 727-746. Noonan, Caitriona (2013) Piety and Professionalism: the BBC's changing religious mission (1960-1979). Media History. Vol. 19, no.2, pp: 196-212.

Ofcom (2005) Religious Programmes: A Report of the Key Findings of a Qualitative Research Study. http://stakeholders.ofcom.org.uk/binaries/research/radioresearch/religious-programmes.pdf Accessed 29 May 2013.

Ofcom (2013) Public Service Broadcasting Annual Report 2013.

http://stakeholders.ofcom.org.uk/broadcasting/reviews-investigations/public-servicebroadcasting/annrep/psb13 Accessed 27 January 2014.

Padovani, Cinzia \& Tracey, Michael (2003) Report on the Conditions of Public Service Broadcasting. Television and New Media. Vol. 4, No. 2, pp: 131-153. Schlesinger, Philip (2004) Do Institutions Matter for Public Service Broadcasting. http://stakeholders.ofcom.org.uk/binaries/consultations/psb2/annexes/wp2schles.pdf Accessed 12 June 2013.

Paquette, Jonathan (ed.) (2012) Cultural Policy, Work and Identity: The creation, renewal and negotiation of professional subjectivities. Farnham: Ashgate.

Steemers, Jeanette (2010) The BBC's role in the changing production ecology of preschool television in Britain. Television and New Media. Vol. 11, No. 1, pp: 37-61. Thompson, Mark (2005) Speech to the Churches' Media Conference, The Hayes Conference Centre, Derbyshire. 6 June.

http://www.bbc.co.uk/pressoffice/speeches/stories/thompson_churches.shtml Accessed 8 August 2011.

Tunstall, Jeremy (1993) Television Producers. London: Routledge.

Waisbord, Silvio (2012) Reinventing Professionalism: Journalism and news in global perspective. Cambridge: Polity Press.

Wolfe, Kenneth M. (1984) The Churches and the British Broadcasting Corporation 1922 - 1956: the politics of broadcast religion. London: SCM Press.

The Work Foundation (2005) The Tipping Point: How much is broadcast creativity at risk?

http://www.theworkfoundation.com/assets/docs/publications/66 tipping point.pdf Accessed 29 January 2014. 
${ }^{\mathrm{i}}$ In both television and radio there are a number of specialist channels (e.g. God TV, Premier Christian Radio, etc.) which broadcast overtly religious content akin to the US form of televangelism. As these outlets have limited availability they are outside the interests of this research.

ii This output includes repeats and acquisitions. It is worth noting that in 2006 the licence service specified that $\mathrm{BBC}$ One should broadcast at least 80 hours of religious programming each year as part of 112 hours across both BBC One and BBC Two (BBC Trust 2006). This specific quota for BBC One was removed in 2008 .

${ }^{i i i}$ According to Ofcom spend on religious output has fallen by 34\% during 2007-2012 (Ofcom 2013).

${ }^{\text {iv }}$ Thought for the Day is a daily scripted reflection which is broadcast at 7.45a.m. during the Today programme. Lasting two minutes and 45 seconds speakers representing different major faiths offer a spiritual insight on topical issues and news events rooted in the theology of their own tradition. Aside from restricting access to agnostics and atheists, the programme itself regularly provokes debate on its content, contributors and future. For a sample of the content see

http://www.bbc.co.uk/podcasts/series/thought. Thought for the Day does not adhere to any major principles of impartiality and objectivity with many of the contributors referring directly to religious scripture in support of their view linking their broadcasts to a project of proselytising. While Thought for the Day is not narrated by BBC staff, logistically it is co-ordinated by the Department of Religion and Ethics. By placing Thought for the Day in the hands of religious groups, the $\mathrm{BBC}$ is able to distance itself on some levels retaining its professional journalistic conduct for programmes like Sunday.

${ }^{v}$ Ofcom (2013) reports that in-house share of spend on first run originated content for religion increased from 54\% in 2007 to $66 \%$ in 2012 . However, any gain would also need to be considered within an overall fall in spend on religious content during that period. 